\title{
Spontaneous abortions and malformations in the offspring of nurses exposed to anaesthetic gases, cytostatic drugs, and other potential hazards in hospitals, based on registered information of outcome
}

\author{
KARI HEMMINKI, PENTTI KYYRÖNEN, AND MARJA-LIISA LINDBOHM \\ From the Institute of Occupational Health, Haartmaninkatu 1, SF-00290 Helsinki 29, Finland
}

SUMMARY Nurses working in selected departments of general hospitals in Finland were collected from a central register on health personnel in Finland. Using the Hospital Discharge Register and the Register of Congenital Malformations, case nurses were selected who had had a spontaneous abortion $(N=217)$ or a malformed child $(N=46)$ between the years 1973 and 1979. Controls consisted of three nurses who had had a normal birth; the control nurses were matched for age and hospital of employment. Information on exposure in the first trimester of pregnancy was sought through the head nurses of the hospitals. No significant increase in risk of spontaneous abortion or of malformation was observed after exposure to anaesthetic gases (odds ratio for spontaneous abortion 1.2), sterilising gases and soaps, or $x$-rays. Handling of cytostatic drugs did not affect the frequency of spontaneous abortion but was associated with malformations in the offspring. The odds ratio, based on eight cases, was $4.7(p=0.02)$ when the logistic model was adopted. The results suggest that the exposures investigated, other than cytostatic drugs, do not cause a strong reproductive risk. Further studies are needed, particularly on cytostatic drugs.

The effects of anaesthetic gases on reproductive health have been a major concern for the past 15 years. Numerous papers have been published, particularly on the prevalence of spontaneous abortions and malformations in the exposed populations. ${ }^{1-2}$ Most studies of spontaneous abortion have found an association between exposure and frequency of spontaneous abortion. A similar association had also been suggested for malformations, but these associations have not been as consistent as those with spontaneous abortions. However, almost all the published studies have used information gathered from questionnaires, and the response rates have rarely exceeded $80 \% .^{1}$ Such data may be biased as the exposed may be more likely than the non-exposed ${ }^{3-4}$ to report fully unsuccessful pregnancies.

We initiated the present study because recorded data on spontaneous abortions and malformations are available in Finland. Thus the response and reporting bias of the results would be minimal. It was additionally of interest to investigate the possible effects of anaesthetic gases at the present levels of exposure, which are substantially lower than those encountered in the 1960s and early 1970s. As hospital work may also involve other exposures that are possibly harmful to pregnancy, such as cytostatic drugs, sterilising soaps and gases, as well as work arrangements including shift work, these factors also were examined.

\section{Materials and methods}

STUDY SUBJECTS

The subjects for the investigation of spontaneous abortion were selected by linking the Hospital Discharge Register with the Central Register of Health Care Personnel, which is maintained in Finland by the National Board of Health. The Hospital Discharge Register was supplemented with policlinic cases of spontaneous abortion before the linkage. The Central Register of Health Care Personnel includes information on persons with training or employment in health care services, for 
example, physicians, dentists, nurses, and pharmacists. The study population was composed of nurses who had been pregnant between the years 1973 and 1979, and who had worked in anaesthesia surgery, intensive care, operating room or internal medicine department of a general hospital. An individual was defined as a case if she had been treated for spontaneous abortion (diagnoses 643 and 645, International Classification of Diseases (ICD), Eighth Revision; the collection of these diagnoses has been explained elsewhere ${ }^{5}$ ) between the years 1973 and 1979. The total number of cases was 217.

To select subjects for the investigation of congenital malformations, the Central Register of Health Care Personnel was linked with the Register of Congenital Malformations, which is also maintained by the National Board of Health. The study population was defined in the same way as in the study of spontaneous abortions. An initial analysis showed a possible association, with a borderline statistical significance, between the birth of a malformed child and the use of cytostatic drugs. To increase the power of the study, the study population was extended to nurses working in paediatric, gynaecological, cancer, and lung departments. An individual was defined as a case if she had given birth to a malformed child between 1973 and 1979. The total number of cases was 46.

Controls for both studies were selected among nurses who had given birth to a 'healthy' child between 1973 and 1979, and who had not given birth, before or after the birth of a healthy child, to a malformed child, nor had had a spontaneous abortion during the study period, that is, cases were excluded from the control population.

The selection of controls for both studies was performed using individual matching. Three controls for each case were chosen, using minimum distance matching of age (with tolerance of \pm 1.5 years) among nurses who had worked in the same hospital as the case. The total number of controls satisfying these criteria was $\mathbf{5 7 1}$ for the study of spontaneous abortions and 128 for the study of congenital malformations. The majority of cases lacking three controls were over 30 years of age.

\section{QUESTIONNAIRE}

Two mailings of a questionnaire, and one additional mailing for the complementary study on malformations, were sent to the leading head nurses of all general hospitals in Finland. The questionnaires were sent with a covering letter which informed the head nurses that the study concerned possible health problems associated with hospital work. Head nurses were asked to ascertain the occupation of the nurses indicated by name and whether they had been. exposed to the listed exposures during a given three months' period (the period was the first trimester of $\Omega$ the nurse's pregnancy). The head nurses were noto informed whether an individual in question was a case or a control. Information was requested on exposure to: anaesthetic gases (nitrous oxide, halothane, other), sterilising agents (ethylene oxide, $工$ glutaraldehyde, formaldehyde), disinfectant soaps (names were requested), cystostatic drugs, and $x$-ray radiation. The questionnaire also requested information on work arrangements (no shift work, $\stackrel{(?)}{+}$ rotating 2-shift, rotating 3-shift, permanent night $\bar{C}$ shift, telephone duty, description of other work arrangement) of the study individuals.

STATISTICAL METHODS

The logistic model for individually matched data, based on the conditional likelihood function, ${ }^{6}$ was. adopted in both studies. The tests for significance $\overrightarrow{\vec{\omega}}$ were evaluated using the maximum likelihood ratio $\stackrel{\circ}{S}$ approximation to a chi-square statistic. Also crude $\stackrel{\odot}{\circ}$ odds ratios (ignoring the matching) were calculated, ? but statistical tests were not performed on them.

\section{Results}

A total of 217 nurses who had had a spontaneo@s abortion were selected for the study. The crude rate of spontaneous abortion (number of spontaneogs $\subseteq$ abortions/number of all pregnancies $\times 100)$ among

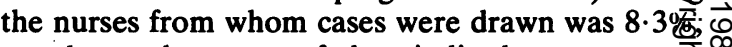
equal to the rate of hospitalised spontaneow or abortions in Finland (8.4\%).

Three control nurses who had had a normal birth were selected for each case. The individual criteria of matching were met by 571 controls (table 1). No information on occupation was available for $12.9 \% \stackrel{\circ}{\mathbb{Q}}$ of the cases and for $12 \cdot 2 \%$ of the controls. The major $\stackrel{2}{\Rightarrow}$ reason for the lack of information was that the nurse had not worked in that particular hospital at the time of pregnancy. Some of the nurses had been studying (4.6\% in the combined series) and some had stayed at home $(2.0 \%)$ at the time inquired. For the remaining nurses $(81.0 \%$ of the combined series) information? on employment and exposure was available; they were the subjects of further analyses.

$X$-rays and anaesthetic gases were the most $\stackrel{\circ}{\beta}$ frequent exposures in this group of nurses (table 2). The odds ratios of spontaneous abortion, calculated 음 for an unmatched series, were 1.1 for exposure to $D$ $x$-rays and 1.2 for exposure to anaethetic gases in early pregnancy. The odds ratios for hexachlorophene and cytostatic drugs were $1 \cdot 1$ and $0 \cdot 8$, respectively. Information was also collected on exposure to sterilising agents: ethylene oxide, $\omega$ glutaraldehyde, and formaldehyde. The odds ratio 
Table 1 Cases of spontaneous abortion and their controls according to type of occupation during early pregnancy

\begin{tabular}{|c|c|c|c|c|c|c|}
\hline & \multicolumn{2}{|c|}{ Cases } & \multicolumn{2}{|c|}{ Controls } & \multicolumn{2}{|c|}{ Combined } \\
\hline & $N$ & $\%$ & $\boldsymbol{N}$ & $\%$ & $N$ & $\%$ \\
\hline $\begin{array}{l}\text { Working } \\
\text { Studying } \\
\text { Housewife }\end{array}$ & $\begin{array}{r}169 \\
15 \\
5\end{array}$ & $\begin{array}{r}77.9 \\
6 \cdot 9 \\
2 \cdot 3\end{array}$ & $\begin{array}{r}469 \\
21 \\
11\end{array}$ & $\begin{array}{r}82 \cdot 1 \\
3 \cdot 7 \\
1 \cdot 9\end{array}$ & $\begin{array}{r}638 \\
36 \\
16\end{array}$ & $\begin{array}{r}81 \cdot 0 \\
4.6 \\
2.0\end{array}$ \\
\hline $\begin{array}{l}\text { Occupation } \\
\text { identified } \\
\text { Occupation } \\
\text { not identified }\end{array}$ & $\begin{array}{r}189 \\
28\end{array}$ & $\begin{array}{l}87 \cdot 1 \\
12 \cdot 9\end{array}$ & $\begin{array}{r}501 \\
70\end{array}$ & $\begin{array}{l}87 \cdot 8 \\
12 \cdot 2\end{array}$ & $\begin{array}{l}690 \\
98\end{array}$ & $\begin{array}{l}87 \cdot 6 \\
12 \cdot 4\end{array}$ \\
\hline Total & 217 & $100 \cdot 0$ & 571 & $100 \cdot 0$ & 788 & $100 \cdot 0$ \\
\hline
\end{tabular}

for glutaraldehyde was $1 \cdot 1$, for ethylene oxide $0 \cdot 6$, and for formaldehyde $0 \cdot 6$. Few nurses had been involved in sterilising instruments and most of them had used only instruments that had been sterilised by, for example, ethylene oxide, and had probably been exposed to negligible levels.

Most nurses in the study population had had work arrangements other than normal day work (table 3 ). Work in rotating 3-shifts was the most common, and the odds ratio of spontaneous abortion was $1 \cdot 2$. The odds ratio in the permanent "night work" category was 1.7 and in "telephone duty" 1.4. There were relatively few spontaneous abortions in the latter two work categories, particularly in the night work category.

Odds ratios of the matched series for the variables investigated are shown in table 4 . The matched odds ratios deviated only a little from the unmatched. The odds ratios for exposure to anaesthetic gases and $x$ rays were slightly above unity, though without statistical significance.

As attempts were made in the 1970 s to reduce the concentration of waste anaesthetic gases in operating theatres by scavenging systems and increased ventilation, it is of interest to compare the odds ratios for spontaneous abortion in the early and late periods of the decade. Using the unmatched series, the odds ratio of spontaneous abortion for nurses exposed to anaesthetic gases was 1.05 in $1973-6$ and 1.23 in 1977-9 (not shown). A similar result was obtained when the year was analysed as a continuous interaction variable with exposure to anaesthetic gases in the logistic model. The odds ratios for this interaction variable ranged between 1.05 and 1.20

Table 2 Proportion of exposed pregnancies among the cases of spontaneous abortion and their controls (exposed/all pregnancies $(\%)$ ) and crude odds ratio

\begin{tabular}{|c|c|c|c|c|}
\hline Exposure & Cases & Controls & Combined & $\begin{array}{l}\text { Crude odds } \\
\text { ratio* }\end{array}$ \\
\hline Anaesthetic gases & $55 / 169(32 \cdot 5)$ & $136 / 469(29.0)$ & $191 / 638(30 \cdot 0)$ & $1 \cdot 2$ \\
\hline \multicolumn{5}{|l|}{$\begin{array}{l}\text { Sterilising agents or } \\
\text { sterilised instruments }\end{array}$} \\
\hline Ethylene oxide & $7 / 164 \quad(4 \cdot 3)$ & $30 / 467 \quad(6 \cdot 4)$ & $37 / 631 \quad(5.9)$ & 0.6 \\
\hline Glutaraldehyde & $34 / 164(20 \cdot 7)$ & $88 / 464(19.0)$ & $122 / 628(19 \cdot 4)$ & 1.0 \\
\hline Formaldehyde & $6 / 164(3 \cdot 7)$ & $24 / 464 \quad(5 \cdot 2)$ & $30 / 628(4 \cdot 8)$ & 0.6 \\
\hline Hexachlorophene ${ }^{* *}$ & $31 / 150(20 \cdot 7)$ & $82 / 428(19.2)$ & $113 / 578(19.6)$ & $1 \cdot 1$ \\
\hline Cytostatic drugs & $12 / 163 \quad(7 \cdot 4)$ & $41 / 454 \quad(9 \cdot 0)$ & $53 / 617 \quad(8.6)$ & 0.8 \\
\hline$x$ rays** & $58 / 159(36 \cdot 5)$ & $150 / 447(33.6)$ & $208 / 606(34 \cdot 3)$ & $1 \cdot 1$ \\
\hline
\end{tabular}

* Compared with unexposed individuals within each exposure category.

$\dagger$ Daily exposure.

$\uparrow$ Exposure at least once a week.

**Frequency of exposure unspecified.

Table 3 Proportion of various work arrangements in pregnancies of the cases of spontaneous abortion and their controls (work arrangement/all pregnancies (\%) and crude odds ratio

\begin{tabular}{|c|c|c|c|c|}
\hline Work arrangement & Cases & Controls & Combined & $\begin{array}{l}\text { Crude odds } \\
\text { ratio* }\end{array}$ \\
\hline $\begin{array}{l}\text { Rotating 3-shift } \\
\text { Permanent night work } \\
\text { Telephone duty } \\
\text { Day shift or rotating 2-shift }\end{array}$ & $\begin{array}{r}101 / 162(62 \cdot 3) \\
4 / 162(2 \cdot 5) \\
27 / 162(16 \cdot 7) \\
30 / 162(18 \cdot 5)\end{array}$ & $\begin{array}{r}290 / 462(62 \cdot 8) \\
8 / 462(1 \cdot 7) \\
63 / 462(13 \cdot 6) \\
101 / 462(21 \cdot 9)\end{array}$ & $\begin{array}{r}391 / 624(62 \cdot 7) \\
12 / 624(1 \cdot 9) \\
90 / 624(14 \cdot 4) \\
131 / 624(21 \cdot 0)\end{array}$ & $\begin{array}{l}1 \cdot 2 \\
1 \cdot 7 \\
1 \cdot 4 \\
1 \cdot 0\end{array}$ \\
\hline
\end{tabular}

"Compared with the category "day shift or rotating 2-shift." 
Table 4 Odds ratios of spontaneous abortion in the matched series controlling for effects of other variables by linear logistic regression

\begin{tabular}{|c|c|c|c|}
\hline Variable & Regression coefficient & Odds ratio & $95 \%$ confidence limits \\
\hline $\begin{array}{l}\text { Anaesthetic gases } \\
\text { Sterilising agents } \geq \text { weekly } \\
\text { Cytostatic drugs }<\text { weekly } \\
\text { Cytostatic drugs } \geq \text { weekly } \\
x \text { rays } \\
\text { Hexachlorophene } \\
\text { Telephone duty } \\
\text { 3-shift }\end{array}$ & $\begin{array}{r}0.221 \\
-0.325 \\
0.075 \\
-0.284 \\
0.110 \\
-0.054 \\
0.538 \\
0.389\end{array}$ & $\begin{array}{l}1 \cdot 2 \\
0 \cdot 7 \\
1 \cdot 1 \\
0 \cdot 8 \\
1 \cdot 1 \\
0 \cdot 9 \\
1 \cdot 7 \\
1 \cdot 5\end{array}$ & $\begin{array}{l}0 \cdot 7-2 \cdot 4 \\
0 \cdot 4-1 \cdot 3 \\
0 \cdot 6-1 \cdot 8 \\
0 \cdot 3-1 \cdot 7 \\
0 \cdot 6-1 \cdot 9 \\
0 \cdot 5-1 \cdot 8 \\
0 \cdot 8-3 \cdot 8 \\
0 \cdot 9-2 \cdot 5\end{array}$ \\
\hline
\end{tabular}

(1979 versus 1973) in different models, showing no evidence of a decreasing trend during the period 1973-9 (not shown).

The nurses selected for study had had 46 births for which notifications had been sent to the Finnish Register of Congenital Malformations. Of these, 38 had worked during the first trimester of pregnancy and they constituted the study subjects together with 99 working controls, who had borne a healthy child (table 5).

As seen in table 6, the number of nurses exposed to various substances is relatively small. The crude odds ratios for $x$ rays and anaesthetic gases were 1.0 and
Table 5 Cases bearing a malformed child and their controls according to type of occupation during early pregnancy

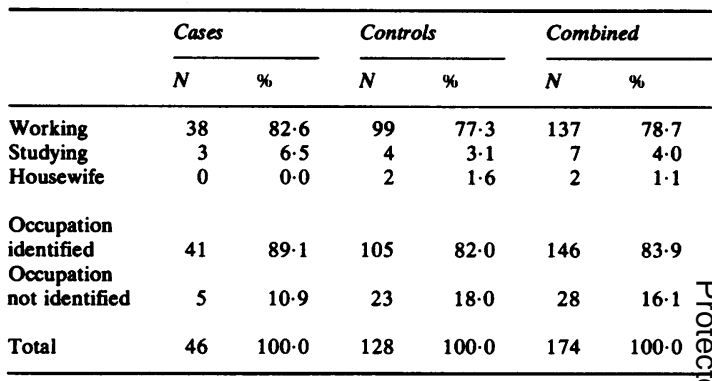

Compared with unexposed individuals within each exposure category.

$\div$ Daily exposure.

†xposure at least once a week.

Table 7 Odds ratios of malformations in the matched series controlling for effects of other variables by linear logistic regression

\begin{tabular}{|c|c|c|c|c|}
\hline Variable & Regression coefficient & Odds ratio & $P$-value & $95 \%$ confidence limits \\
\hline $\begin{array}{l}\text { Anaesthetic gases } \\
\text { Cytostatic drugs }<\text { weekly } \\
\text { Cytostatic drugs } \geq \text { weekly } \\
\text { Sterilising agents } \\
x \text { rays } \\
\text { Hexachlorophene }\end{array}$ & $\begin{array}{r}0.165 \\
0.686 \\
1.539 \\
0.496 \\
-0.226 \\
-1 \cdot 115\end{array}$ & $\begin{array}{l}1 \cdot 2 \\
2 \cdot 0 \\
4 \cdot 7 \\
1 \cdot 6 \\
0 \cdot 8 \\
0 \cdot 3\end{array}$ & $\begin{array}{l}0.80 \\
0 \cdot 17 \\
0.02 \\
0.52 \\
0.70 \\
0.20\end{array}$ & $\begin{array}{l}0 \cdot 3-4 \cdot 6 \\
0 \cdot 7-5 \cdot 3 \\
1 \cdot 2-18 \cdot 1 \\
0 \cdot 4-7 \cdot 5 \\
0 \cdot 3-2 \cdot 4 \\
0 \cdot 1-1 \cdot 8\end{array}$ \\
\hline
\end{tabular}

Table 6 Proportion of exposed pregnancies among the cases with malformed children and their controls

\begin{tabular}{|c|c|c|c|c|}
\hline \multirow[b]{2}{*}{ Exposure } & \multicolumn{3}{|c|}{ Exposed/all pregnancies (\%) } & \multirow{2}{*}{$\begin{array}{l}\text { Odds } \\
\text { ratio* }\end{array}$} \\
\hline & Cases & Controls & Combined & \\
\hline Anaesthetic gases & $9 / 38(23.7)$ & $26 / 99(26 \cdot 3)$ & $35 / 137(25 \cdot 5)$ & 0.9 \\
\hline \multicolumn{5}{|l|}{$\begin{array}{l}\text { Sterilising agents or } \\
\text { sterilised instrumentsł }\end{array}$} \\
\hline $\begin{array}{l}\text { Ethylene oxide } \\
\text { Glutaraldehyde } \\
\text { Formaldehyde }\end{array}$ & $\begin{array}{l}2 / 34(5 \cdot 9) \\
5 / 34(14 \cdot 7) \\
3 / 34(8 \cdot 8)\end{array}$ & $\begin{array}{r}4 / 95(4 \cdot 2) \\
17 / 95(17 \cdot 9) \\
5 / 95(5 \cdot 3)\end{array}$ & $\begin{array}{r}6 / 129(4 \cdot 7) \\
22 / 129(17 \cdot 1) \\
8 / 129(6 \cdot 2)\end{array}$ & $\begin{array}{l}1.4 \\
0.8 \\
1 \cdot 8\end{array}$ \\
\hline Hexachlorophene & $2 / 33 \quad(6 \cdot 1)$ & $17 / 91(18.7)$ & $19 / 124(15 \cdot 3)$ & $0 \cdot 3$ \\
\hline $\begin{array}{l}\text { Cytostatic drugs } \\
\text { Less than once a week } \\
\text { At least once a week }\end{array}$ & $\begin{array}{r}11 / 38(28 \cdot 9) \\
8 / 38(21 \cdot 1)\end{array}$ & $\begin{array}{r}20 / 99(20 \cdot 2) \\
8 / 99(8 \cdot 1)\end{array}$ & $\begin{array}{l}31 / 137(22.6) \\
16 / 137(11.7)\end{array}$ & $\begin{array}{l}2 \cdot 1 \\
3 \cdot 7\end{array}$ \\
\hline$x$ rays & $13 / 35(37 \cdot 1)$ & $35 / 95(36 \cdot 8)$ & $48 / 130(36 \cdot 9)$ & 1.0 \\
\hline
\end{tabular}


0.9 , respectively. The results for exposure to cytostatic drugs were also based on small numbers. Eleven malformed children were born to women who had handled cytostatic drugs less frequently than once a week (odds ratio $2 \cdot 1$ ) and eight to those who had been exposed more frequently (odds ratio $3 \cdot 7$ ).

Analysis of the association of the various exposures with malformations in a matched series indicated that the odds ratio for anaesthetic gases was slightly above one $(1 \cdot 2)$ and for $x$ rays slightly below one $(0 \cdot 8)$. When pregnant nurses handled cytostatic drugs less frequently than once a week, the odds ratio was 2.0 (ns); for a more frequent exposure the odds ratio was $4 \cdot 7$, which was statistically significant $(p=0.02)$.

The types of malformation in children born to nurses who had been exposed to cytostatic drugs at least once a week were malformations of ear, face, and neck (ICD 745, 2 children), heart (ICD 746, one child), urinary organs (ICD 753 , one child), and limbs (ICD 754 and 755, four children). A more detailed list of the malformations is presented in table 8 .

\section{Discussion}

In the present study we investigated the reproductive effects of potentially hazardous exposures in hospitals. The main purpose was to evaluate the effect of anaesthetic gases on spontaneous abortions using objective data of the outcome. Although at least 15 studies have been published on the relation between anaesthetic gases and spontaneous abortion $^{1}$ only one of them was based on confirmed cases of spontaneous abortion. ${ }^{3}$ The latter study found a modest increase in the frequency of spontaneous abortion in the exposed group of nurses $(14.2 \% v 9.8 \%$ in the control group: the difference was statistically insignificant). Several other studies, based on spontaneous abortions reported subjectively, have found significant differences in the rates of spontaneous abortion between anaesthetic personnel and the control population ${ }^{7-14}$ even though negative studies also exist. ${ }^{15-20}$

Because response and reporting bias may be present in interview and questionnaire studies, ${ }^{3-4}$ studies based on objective sources of spontaneous abortion are helpful in corroborating the findings.

Several studies have also considered the possibility that anaesthetic gases could cause malformations in the offspring when exposed in utero. The data have been more conflicting than in the case of spontaneous abortion, ${ }^{2}$ and the same reservations about the study design appear to weaken both types of study.

In this study the exposure data were obtained from questionnaires sent to the head nurses of the hospitals. The covering letter indicated that the study concerned possible health problems of hospital work. It was not revealed that reproductive effects were of primary interest, nor was any information given to distinguish cases from controls. For some of the information requested (eg, exposure to anaesthetic gases and work arrangements) the head nurses could consult log books to obtain directly the level of exposure. For some other exposures, such as the use of cytostatic drugs, records were rarely available but log books on work with cancer patients implied exposure. These data on exposure appear to be

Table 8 Numbers of different types of malformation according to exposure to cytostatic drugs

\begin{tabular}{|c|c|c|c|c|c|}
\hline \multirow{2}{*}{$\begin{array}{l}\text { Type of malformation } \\
\text { (ICD code)* }\end{array}$} & \multicolumn{5}{|c|}{ Exposure to cytostatic drugs } \\
\hline & $\geqslant$ weekly & $<$ weekly & Not exposed & Exposure unknown & Total \\
\hline $\begin{array}{l}\text { Central nervous system } \\
(740-743)\end{array}$ & - & - & 1 & 1 & 2 \\
\hline $\begin{array}{l}\text { Ear, face, and neck } \\
\text { (745) }\end{array}$ & 2 & - & - & - & 2 \\
\hline Heart & 1 & - & 1 & 1 & 3 \\
\hline $\begin{array}{l}\text { Cleft lip and/or palate } \\
\text { (749) }\end{array}$ & - & 1 & - & - & 1 \\
\hline $\begin{array}{l}\text { Digestive system } \\
(750,751)\end{array}$ & - & 1 & 1 & - & 2 \\
\hline $\begin{array}{l}\text { Genital organs } \\
(752)\end{array}$ & - & 1 & 2 & 1 & 4 \\
\hline $\begin{array}{l}\text { Urinary organs } \\
\text { (753) }\end{array}$ & 1 & - & - & 2 & 3 \\
\hline Limbs & 4 & 8 & 11 & 2 & 25 \\
\hline $\begin{array}{l}\text { Down's syndrome } \\
(759 \cdot 30)\end{array}$ & - & - & 3 & 1 & 4 \\
\hline Total & 8 & 11 & 19 & 8 & 46 \\
\hline
\end{tabular}

*The main diagnosis from the notification of malformation. 
reasonably accurate and avoid some of the problems encountered when the study subjects themselves determine the level of exposure. ${ }^{4}$

The present study detected no significant increase in the frequency of spontaneous abortions and malformations in the offspring of nurses exposed to anaesthetic gases but as the odds ratio was above unity, a small effect from anaesthetic gases cannot be ruled out. The power of our study to detect a two-fold odds ratio was above $85 \%$, as calculated for a $2 \times 2$ table with $25 \%$ exposure frequency in the control series, ${ }^{21}$ indicating that a strong effect of anaesthetic gases on spontaneous abortion was unlikely. The fact that there appeared to be no decreasing trend in the frequency of spontaneous abortion in the 1970s, when attempts have been made all over Finland to reduce the levels of anaesthetic gases in the ambient air of operating theatres, prompts a similar conclusion. A potential bias to record spontaneous abortion differently in time is unlikely, since no increasing or decreasing trend can be observed in the ratio of spontaneous abortions to births in the Finnish Hospital Discharge Register data.

There has been no systematic effort to determine the concentrations of anaesthetic gases in the ambient air of operating theatres in Finnish hospitals. An ad hoc study in the early 1970 s surveyed 14 operating theatres and found mean halothane concentrations of 10.9 and $0.8 \mathrm{ppm}$ in theatres without and with a scavenging system, respectively. ${ }^{22}$ The respective median concentrations were 6.5 and $0.7 \mathrm{ppm}$. According to the same study, the mean concentrations of nitrous oxide were 1080 and $165 \mathrm{ppm}$ in theatres without and with a scavenging system, respectively; the respective median concentrations were 710 and $115 \mathrm{ppm}$.

No significant differences were found in the frequency of spontaneous abortions or malformations in the offspring in connection with sterilising gases, hexachlorophene or $x$ rays. Based on a large study of sterilising personnel, we have previously reported that exposure to ethylene oxide was associated with an increased risk of spontaneous abortion..$^{23}$ Unfortunately, the present study failed to distinguish between sterilising work (where a daily exposure to $1 \mathrm{ppm}$ or less may take place) and the use of instruments sterilised by ethylene oxide (where very small exposures could be expected). As only one nurse could be ascertained to be involved in sterilisation, the study provided no information on the effects of ethylene oxide. A Swedish study suggested that the use of hexachlorophene was associated with an increase in central nervous system malformations. ${ }^{24}$ This finding could not be confirmed in another Swedish study ${ }^{25}$ nor in the present study. Two malformed children were born to nurses exposed to hexachlorophene, but neither had a malformation of the central nervous system. However, we have to stress the low statistical power of our study on malformations: only very potent effects could have been noted.

A previous study found an association (risk ratio 3.19) between shift work and spontaneous abortion in laboratory personnel. ${ }^{26}$ The present study also examined the possible effects of work arrangements other than normal daily work. Work in three shifts was quite common in the population of nurses studied. The odds ratio for spontaneous abortion was slightly above one $(\sim 1 \cdot 5)$. Night work and telephone duty also tended to produce odds ratios above one, but the relatively small number of pregnancies does not justify any definite conclusions.

Nurses handling cytostatic drugs have been exposed to active ingredients, as had been suggested by an increase in their urinary mutagenicity. ${ }^{27}$ Furthermore, the nurses handling cytostatic drugs have had more sister chromatid exchanges ${ }^{28}$ and chromosomal aberrations in lymphocytes compared to the control population. ${ }^{29}$ The present study detected an increase in malformations of the ${ }^{0}+\overrightarrow{0}$ offspring when the nurses had reportedly handleo $\vec{D}$ cytostatic drugs. The increase appeared to be related? to the frequency of use, which suggests that thed finding is not a product of chance. No increase was $\vec{c}$ observed in the frequency of spontaneous abortion,$\subseteq$ but it should be noted that spontaneous abortionso क्ष were collected from nurses working in departments. $\vec{\varphi}$ (anaesthesia, surgery, intensive care, operating of theatre, and internal medicine) where exposure to cytostatic drugs was relatively uncommon. By contrast, the study on malformations was extended in the latter phase to the department of extensive cancer treatment (eg, oncology departments), where higher exposures might have taken place. The initial analysis of malformations was performed on 30 cases and 81 controls, of which five cases and four controls had been exposed to cytostatic drugs at least once a week. The odds ratio in the logistic analysis was 5.9 $(p \simeq 0.06)$. We considered that it was important to discover whether or not the high odds ratio was the product of chance by enlarging our study population. The latter study population consisted of 16 cases and 47 controls, of which three cases and four controls had handled cytostatic drugs at least once a week. The odds ratio was $3 \cdot 4(p \simeq 0 \cdot 19)$. Since the data were collected in the same manner for both the former and latter study population, and since no results were released before completing the study, we considered it justifiable to combine the data.

We are in the process of reassessing the possible role of cytostatic drugs in spontaneous abortions in hospitals, where most extensive cancer 
chemotherapy is being carried out. Even though the present study was designed to be devoid of most sources of bias recognised in reproductive studies, ${ }^{4}$ some unrecognised ones may still operate and may contribute to the findings.

Although hygienic measures to reduce the exposure of hospital personnel to cytostatic drugs, many of which are recognised carcinogens and teratogens, ${ }^{30}$ appears highly justified, we suggest that our findings should be confirmed in an independent series.

We thank Dr S Selevan for her comments. This study was supported by the Medical Research Council, Finland.

\section{References}

${ }^{1}$ Axelsson, G. Miscarriage after occupational exposure, aspects of risk assessment in retrospective studies. Acad diss, Gothenburg 1983.

${ }^{2}$ Vessey MP, Nunn JF, Occupational hazards of anaesthesia. $\mathrm{Br} \mathrm{Med} J$ 1980, 281: 696-8.

${ }^{3}$ Axelsson G, Rylander R. Exposure to anaesthetic gases and spontaneous abortions: response bias in a postal questionnaire study. Int $J$ Epidemiol 1982, 11: 250-6.

${ }^{4}$ Hemminki K, Axelson O, Niemi M-L, Ahlborg G. Assessment of methods and results of reproductive occupational epidemiology: spontaneous abortions and malformations in the offspring of working women. Am J Ind Med 1983, 4: 293-307.

${ }^{5}$ Hemminki K, Kyyrönen P, Niemi M-L, Koskinen K. Sallmén M, Vainio $H$. Spontaneous abortions in an industrialised community in Finland. Am J Public Health 1983, 73: 32-7.

${ }^{6}$ Breslow NE, Day NE. Statistical methods in cancer research. Vol 1. The analysis of case-control studies. Lyon: IARC, 1980.

${ }^{7}$ Askrog V, Harvald B. Teratogen effect of inhalationsanaestetika. Nordisk Medicin 1970, 83: 498-500.

${ }^{8}$ Cohen EN, Bellville JW, Brown BW. Anesthesia, pregnancy, and miscarriage: a study operating room nurses and anesthetists. Anesthesiology 1971, 35: 343-7.

${ }^{9}$ Cohen EN, Brown BW, Bruce DL, Cascorbi HF, Corbett TH, Jones TW, Whitcher $\mathrm{CH}$. Occupational disease among operating room personnel: a national study. Anesthesiology 1974, 41: 321-40.

${ }^{10}$ Cohen EN, Brown BW, Bruce DL, Cascorbi HF, Corbett TH, Jones TW, Whitcher CH. A survey of anesthetic health hazards among dentists. JADA 1975, 90: 1291-6.

${ }^{11}$ Cohen EN, Brown BW, Wu ML, et al. Occupational disease in dentistry and chronic exposure to trace anesthetic gases. $J A D A$ 1980, 101: 21-31.
${ }^{12}$ Knill-Jones RP, Moir DD, Rodrigues LV, Spence AA. Anesthetic practice and pregnancy. Lancet 1972, 1: 1326-8.

${ }^{13}$ Rosenberg P, Kirves A. Miscarriages among operating theatre staff. Acta Anesthesiol Scand 1972, 53: 37-42.

${ }^{14}$ Göthe CJ, Dahlgren B-E, Hallen B, Olander L, Ovrum P, Westerholm P. Narcotic gases as industrial hazard (in Swedish). Läkartidningen 1976, 73: 2553-63.

${ }^{15}$ Tomlin PJ. Health problems of anaesthetists and their families in the West Midlands. Br Med J 1979. 1: 779-4.

${ }^{16}$ Knill-Jones RP, Newman BJ, Spence AA. Anesthetic practice and pregnancy. Lancet 1975, 2: 807-9.

${ }^{17}$ Pharoah POD, Alberman E, Doyle P, Chamberlain G. Outcome of pregnancy among women in anesthetic practice. Lancet 1977, 1: 34-6.

${ }^{18}$ Rosenberg PH, Vänttinen H. Occupational hazards to reproduction and health in anesthetists and paediatricians. Acta Anaesthesiol Scand 1978, 22: 202-7.

${ }^{19}$ Lauwerys R, Siddons M, Misson CB, et al. Anaesthetic health hazards among Belgian nurses and physicians. Int Arch Occup Environ Health 1981, 48: 125-203.

${ }^{20}$ Heidam LZ. Spontaneous abortions among dental assistants, factory workers, painters, and gardening workers: a follow up study. J Epidemiol Community Health 1984, 38: 149-55.

${ }^{21}$ Rothman KJ, Boice JD. Epidemiologic analysis with a programmable calculator, New Edition. Boston, Massachusetts: Epidemiology Resources, Inc, 1982.

${ }^{22}$ Pfäffli P, Nikki P, A hlman K. Halothane and nitrous oxide in endtidal air and venous blood of surgical personnel. Ann Clin Res 1976, 4: 273-7.

${ }^{23}$ Hemminki K, Mutanen P, Saloniemi I, Niemi M-L, Vainio H. Spontaneous abortions in hospital staff engaged in sterilising instruments with chemical agents. Br Med J 1982, 285: 1461-3.

${ }^{24}$ Halling $H$. Suspected link between exposure to hexachloropene and malformed infants. Ann NY Acad Sci 1979, 320: 426-35.

${ }^{25}$ Baltzar B, Ericson A, Källen B. Delivery outcome in women employed in medical occupations in Sweden. $J$ Occ Med 1979, 21: 543-8.

${ }^{26}$ Axelsson G, Lütz C, Rylander R. Exposure to solvents and pregnancy outcome among university laboratory employees. Br J Ind Med 1984, 3: 305-12.

${ }^{27}$ Falck K, Gröhn P, Sorsa M, Vainio H, Heinonen E, Holsti L. Mutagenicity in urine of nurses handling cytostatic drugs. Lancet 1979, 1: 1250-1.

${ }^{28}$ Norppa H, Sorsa M, Vainio H, Gröhn P, Heinonen E, Holsti L, Nordman E. Increased sister chromatid exchange frequencies in lymphocytes of nurses handling cytostatic drugs. Scand J Work Environ Health 1980, 60: 299.

${ }^{29}$ Sorsa M, Norppa H, Vainio H. Induction of sister chromatid exchanges among nurses handling cytostatic drugs. In Bridges, BA, et al, eds Indicators of genotoxic exposure in man and in animals. Branbury report 13. New York: Cold Spring Harbor Laboratory, 1982, 341-54.

${ }^{30}$ International Agency for Research on Cancer. IARC Monographs on the evaluation of the carcinogenic risk of chemicals to humans: chemicals, industrial processes and industries associated with cancer in humans. IARC Monographs, Vols 1 to 29: Suppl 4. Lyon: IARC, 1982. 